\title{
Pobreza, crédito e redes sociais na Europa pré-industrial
}

Poverty, credit and social networks in pre-industrial Europe

Pauvreté, crédit et réseaux sociaux en Europe préindustrielle

Pobreza, crédito y redes sociales en Europa pre-industrial

\section{Laurence Fontaine [1]}

$\mathrm{P}$ ara entender o papel do crédito na Europa moderna, escolhemos um olhar a partir dos pobres, já que a primeira demanda de quem empobrece, tanto no presente como no passado, é solicitar crédito e prazos para pagamento (Fontaine, 2008). Entretanto, antes de entrar nas estratégias das famílias, a primeira questão que se coloca é saber como eram definidos e se definiam os pobres.

Na idade média, os textos literários bem como os pregadores, os cronistas ou a linguagem administrativa chamavam de pobres, de forma usual, aqueles que viviam do seu trabalho. O sentido da palavra não é só econômico: o pobre é aquele que padece, que está na infelicidade. ${ }^{2}$ No final do século XVII, o dicionário de Furetière definia a pobreza como a "falta de bem, de fortuna" (Furetière, 1690). De fato, todas as definições dos homens políticos da época, e, em particular, na famosa análise de Vauban - Projeto de uma dízima real -, de 1707, insistiam no fato de que pobre é aquele que, possuindo tão somente seu trabalho, está suscetível se, por um motivo qualquer, não puder mais trabalhar. No final do século XVIII, em 1788, Condorcet confirmava a mesma percepção, definindo o pobre como "aquele que não possui nem bens nem mobília e que está fadado a cair na miséria ao mínimo acidente". ${ }^{3}$ Essas definições eruditas encontram-se com aquelas dos pobres falando de si: os moradores da Roma do século XVII diziam-se pobres quando somente tinham o seu trabalho para subsistir (Ago, 1998, p. 82-89). Aliás, a época moderna utilizou outros termos, os de indigente ou de mendigo, para designar aqueles que caíram na pobreza (Gutton, 1971, p. 8-10). A pobreza era tanto um processo potencial quanto um estado, o que quer dizer que para compreendê-la, é preciso não somente estudar os mecanismos de empobrecimento, mas também o que os indivíduos podem fazer para minimizar os riscos, para frear e retardar a degradação de suas condições nos períodos de crise. 
Os historiadores não se deixaram enganar, mas, curiosamente, raramente se interessaram pelos meios que permitiam aos indivíduos resistir e, em particular, ao modo como eles podiam utilizar os mecanismos financeiros. Olhar o que diz a historiografia da pobreza mostra quanto as questões dos historiadores são filhas de seu tempo. Encabeçando os temas mais abordados pela historiografia estão as maneiras como a sociedade tratava seus pobres. A caridade privada e as instituições caritativas foram os aspectos que durante um longo tempo receberam maior atenção. Mais recentemente, os historiadores têm trabalhado em uma dupla direção: de um lado, pensar o fenômeno na sua dimensão política e seguir a questão social (Proccacci, 1993; Castel, 1995), de outro lado, optar por uma perspectiva mais dinâmica e mais individual e não mais se contentar com o ponto de vista do rico que dava esmola e criava instituições, mas adotar também o ponto de vista do pobre que tenta combater os mecanismos de empobrecimento.

Nessa segunda direção, estudar os ciclos de vida e de que maneiras os pobres utilizaram as instituições foram inicialmente privilegiados (Henderson \& Wall, 1994; Lombardi, 1988; Woolf, 1986; Jütte, 1994; Carbonell i Esteller, 1997), depois complementados por uma teoria da "economia dos expedientes" (economy of makeshift) que insistia sobre as estratégias desviantes - roubo, contrabando, prostituição, abandono de crianças, etc. - utilizadas para garantir a sobrevivência (Hufton, 1974). Hoje em dia, há mais interesse em se compreender não somente os meios criminosos, esses que os arquivos judiciários mostram, mas também os aspectos mais positivos, ou seja, como os pobres criavam estratégias econômicas para prevenir a miséria e mobilizavam as redes sociais para lutar contra as lógicas do empobrecimento (Fontaine \& Schlumbohm, 2000). Contudo, são raras as fontes que falam dos pobres e de seus modos de viver. ${ }^{4}$

Se o balanço dessa historiografia é notável na riqueza e na diversidade, vale, entretanto, sublinhar quanto ela tem, no conjunto, dedicado pouca atenção aos mecanismos financeiros e às redes sociais. De fato, na análise das relações entre ricos e pobres, os estudos se limitam tão somente às manifestações da caridade, ainda que todas salientem o papel da patronagem e sublinhem o quanto a sociedade antiga se fundamentava nas relações interpessoais. E, de fato, o contraste entre o pobre e o vagabundo é, ao longo do antigo regime, o que determina o estabelecimento das fronteiras sociais da comunidade. Na idade média, tolerava-se o mendigo e odiava-se o vagabundo. $\mathrm{O}$ vagabundo era o "sem confissão", aquele que não tinha ninguém para testemunhar a seu favor, que não tinha nenhum laço social, e para existir socialmente era fundamental ter alguém que respondesse por você. Não ser reconhecido

\footnotetext{
${ }^{4}$ Stuart Woolf (1986, p. 20) menciona esses mecanismos informais de defesa, sublinhando quanto a documentação não permite de se aproximar deles e Robert Jütte (1994, cap. 4) dedica a eles um capítulo geral. Montserrat Carbonell i Esteller (1997, p. 161-168) reencontrou os laços familiares dos assistidos da Santa Casa de Barcelona no último terço do século XVIII.
} 
por ninguém, não poder se confessar ligado a ninguém é o signo do isolamento e da rejeição social. ${ }^{5}$

Podemos adiantar as várias razões para justificar a pouca atenção dada pelos historiadores às redes sociais que protegiam os homens do destino, dos "sem confissão" (vagabundos). Mencionarei duas: a primeira remete à historiografia que foi por muito tempo filha do "Estado de bem-estar social" (Welfare State) e das três décadas gloriosas (1940-1970). Os historiadores se dedicaram sobretudo a entender a genealogia das proteções sociais e colocaram o trabalho no centro de seus questionamentos. Quando esses sistemas de proteção começaram a ruir, os historiadores - e os anglo-saxões foram os primeiros, nos anos 1990, a se preocuparem com isso - interessaram-se então pela autoajuda (selfhelp), o modo pelo qual os pobres, em um contexto de trabalho irregular, conseguiam se livrar dos apuros sem os auxílios públicos (Horden \& Smith, 1998; Hindle, 2004).

A segunda razão reside no lugar que os historiadores atribuíram à economia na reflexão histórica. De fato, as análises do empobrecimento foram escritas majoritariamente nos anos 1960 e 1970 e se restrigiam, como aliás a grande maioria dos trabalhos históricos da época, a uma causalidade unicamente econômica: os sistemas políticos, sociais e culturais não eram então considerados. A sociedade era descrita como clientelista mas essa qualidade não tinha influência sobre as explicações da pobreza. O social e político somente são reintroduzidos para explicar como os ricos selecionavam seus pobres por meio da patronagem, da proteção e da mediação, colocando assim em evidência a posição social e política do benfeitor. Eles são também reintroduzidos para mostrar como as instituições caritativas pretendiam inculcar os valores deferentes de submissão que as elites esperavam dos grupos menos afortunados (Woolf, 1986, p. 27). Essa desconexão impede de se trabalhar sobre os processos sociais e culturais de exclusão social.

O endividamento é sempre mencionado como um dos mecanismos do empobrecimento, mas, outro traço que une o conjunto da historiografia, o crédito, é considerado como um mecanismo econômico global cujos resultados os historiadores se utilizam a longo prazo. As análises referem-se à ascensão da burguesia que soube aproveitar do endividamento aristocrático e camponês. Mesmo se o estudo dos pobres pode ser conduzido de forma microscópica seguindo os casos individuais, a economia permanece um fenômeno macroscópico nesses estudos, um elemento externo sobre o qual os indivíduos não tinham alcance. A ênfase posta sobre as evoluções longas e a crença que o econômico é um campo autônomo regido por uma racionalidade própria não

\footnotetext{
${ }^{5}$ Mollat, 1978, p. 299. Para Jean-Pierre Gutton e Robert Castel, as definições do vagabundo são estabelecidas mais tardiamente. O termo de vagabundo define-se progressivamente entre os séculos XVI e XVIII: de aquele que vagueia sem domicílio, passa-se, em 1666, àquele que não somente é pobre (sem profissão, sem bens para subsistir), mas além disso é vagabundo mesmo (Gutton, 1971, p. 9-13; Castel, 1995, p. 90-97). Gutton cita a carta, endereçada a uma lavadeira instalada em Lyon, feita por uma empregada que deixou a cidade e se encontrava em Grenoble e não conseguia obter a colocação que the haviam proposto porque não havia ninguém na cidade que pudesse responder por ela. Ela pede para sua amiga lavadeira encontrar sua antiga patroa e suplicar-Ihe "um certificado de serviço e de fidelidade" (p.82).
} 
permitiu ver o quanto as relações econômicas eram também relações sociais e culturais. Daí um déficit de análises individuais que permitiriam seguir os efeitos dos laços de crédito mais perto dos diferentes grupos sociais e de se perguntar se todos os credores, fossem eles nobres, burgueses ou camponeses, tinham as mesmas práticas. Em suma, os historiadores privilegiaram sobre essa questão, as análises macro, constatando transformações estruturais da sociedade, mas não viram como essas transformações agiram no nível individual, impossibilitando-se assim de se compreender a diversidade das linguagens e das práticas. Apesar do superendividamento ser uma das primeiras manifestações da pobreza, a historiografia quase não se interessou por ele, privilegiando a assistência e a caridade. Dessa forma, ela se colocou do ponto de vista do Estado e das elites. Somente muito recentemente os pobres foram colocados no centro das pesquisas sobre a pobreza e foram levadas em consideração as maneiras pelas quais eles podiam pensar, prever e se organizar nas diversas crises que os ameaçaram e os atingiram. De fato, a pobreza sempre foi pensada como um estado enquanto ela é um risco, o que as definições da época dizem aliás muito bem.

Para compreender bem a amplitude das estratégias que cada um poderia utilizar, é útil analisar os elementos que entram nas economias populares bem-sucedidas. Graças aos arquivos familiares conservados, pode-se acompanhar a maneira pela qual uma família de uma pequena cidade do sudoeste da Alemanha, entre 1738 e 1827, atravessou crises econômicas e até mesmo o incêndio que destruiu sua casa. Ernst Jacob Vayhinger, um tecelão de lã (zeugmacher) que viveu entre 1729 e 1791 e escreveu uma crônica entre 1756 e 1784, será nosso exemplo (Frey Jr., 2000. p.115-135). Ernst casou-se aos 25 anos e como presente de casamento, seus pais lhe ofereceram um tear. Dedicou-se à atividade, endividou-se para comprar uma parte da casa de seus pais; paralelamente, alugou pedaços de terra pertencente à cidade cuja cultura o permitiu tornar-se um ativo horticultor e acrescentar alguns campos para o cultivo de cevada e batatas inglesas. Finalmente, criou pássaros: primeiro, pombos e, nos anos difíceis de 1764 e 1766, começou a criar canários. É graças a essa entrada no mercado de luxo - pois a burguesia se apegou a esses pássaros exóticos - que conseguiu atravessar os anos de fome quando os preços dos produtos agrícolas subiram consideravelmente e a fome espreitava. Ter um pé no mercado de grãos o ajudou a resistir à carestia, mas a venda dos canários foi essencial para atravessar esses anos e, em 1772, representava quase a quarta parte dos ganhos anuais. Alguns anos mais tarde, conseguiu comprar a prazo a parte baixa da casa, que alugou até que um incêndio destruiu o bairro em 1782. Ernst se queixou dos prejuízos do incêndio e da dificuldade de reconstruir o térreo e não falou mais em locatários. Antes de morrer, tentou pagar suas próprias dívidas e receber de quem lhe devia para livrar sua descendência desses laços.

Essa economia mostra certos aspectos fundamentais das estratégias populares: a diversificação de atividade e a utilização do mercado. A diversificação 
de atividades é em toda parte a primeira das estratégias. Ela trabalha em um duplo registro: as atividades legais e/ou ilegais e a possibilidade - ou não - de que essas atividades desenvolvam capacidades empresariais. Jacob estava no mercado de múltiplas maneiras, como tecelão, como camponês e como fornecedor de produtos de luxo. Vê-se que conseguiu relações de crédito e que praticou economias de escala ao alugar parte de sua casa para outros. Seria preciso igualmente acrescentar a essas escolhas, múltiplas estratégias de economias que não se veem nos documentos sobre Ernest Jacob Vayhinger, mas que são igualmente centrais.

\section{Os historiadores privilegiaram as análises macro, constatando transformações estruturais da sociedade, mas não viram como essas transformações agiram no nível individual}

Vamos entrar agora nesses diversos elementos:

O mercado. Se estudar a pobreza na Europa moderna entre os séculos XVII e XIX colocou em evidência o papel do mercado nas estratégias de sobrevivência, mostra também a progressiva exclusão dos pobres da maior parte dos mercados aos quais eles tinham tradicionalmente acesso. Vou ilustrar essa evolução apoiando-me sobre o importante mercado do vestuário e dos objetos de segunda mão. Na Europa moderna, a circulação de segunda mão foi dominante no mercado do vestuário e de mobiliário e os pobres foram grandes atores dessas circulações. Antes da chegada da confecção barata no século $\mathrm{XX}$, a economia do vestuário era uma economia do reemprego e não da novidade. As roupas eram raras e preciosas e elas sustentaram um exército de alfaiates que as adaptavam a seus novos donos até o completo esgotamento. Assim, jamais eram descartadas, mas sempre vendidas, alugadas, empenhadas ou ofertadas, e movimentam um comércio muito importante.

Todos entravam nessa economia, tanto aquele que emprestava quanto quem pedia emprestado, e os arquivos da justiça guardam muitos exemplos de homens e de mulheres comuns que aceitaram emprestar ou receber dinheiro contra o penhor de uma roupa ou de uma pequena joia. Alguns inventários post-mortem mostram uma verdadeira atividade de empréstimo quando mulheres do povo morriam deixando um grande número de créditos.

As mulheres foram, aliás, o coração dessa pequena economia, onde a roupa circulava como dinheiro, onde as pessoas alugavam ou penhoravam segundo as necessidades, por serem confrontadas pelo seguinte desafio: por um lado, tinham uma capacidade política, administrativa e judiciária diminuta, que as reduzia a gestões sem brilho e sem imaginação; mas, por outro lado, apesar de tutelas e regulações restritivas, deviam gerir despesas familiares e jogar perpetuamente com necessidades regulares de dinheiro e entradas 
monetárias irregulares; elas deviam fazer tudo isso com orçamentos que raramente elas próprias controlavam. Assim, o papel social das mulheres em uma economia onde as instituições financeiras eram muito pouco desenvolvidas e em uma estrutura jurídica que as marginalizava, explica por que elas animavam, desde a idade média, circuitos de venda e revenda de roupas usadas (Fontaine, 2008, cap. 5).

\section{Estudar a pobreza na Europa moderna entre os séculos XVII e XIX colocou em evidência o papel do mercado nas estratégias de sobrevivência}

Ao lado desse papel de intermediárias, muitas mulheres sobreviviam utilizando seu saber de costureira para retrabalhar roupas de segunda mão; faziam isso a partir da demanda do mercado de usados, como atividade paralela para ganhar alguns trocados, e vendiam as peças assim produzidas - geralmente roupas de crianças - nas ruas e mercados. Mas essas possibilidades se fechavam progressivamente a partir do século XVIII. A exclusão do mercado dos mais pobres era a conjunção de três fenômenos: a luta dos mercadores estabelecidos que queriam se livrar desse pequeno comércio concorrente, o Estado que sabia agarrar todas as possibilidades para cobrar novas taxas e, no século XIX, o surgimento de novas normas de higiene que mudaram o olhar sobre a segunda mão, levantando suspeitas de que as roupas que circulavam traziam doenças e a cólera. A instauração de patentes foi o primeiro golpe dado às numerosas mulheres que viviam da modificação de vestuário em roupas de crianças.

Um processo esclarece muito bem essas transformações: diz respeito a duas mulheres, Marie-Denise Toutain, esposa de um carpinteiro e sua irmã, Antoinette Toutain. Ambas foram acusadas de terem vendido, sem pagar licença, roupas na feira de Meaux, na segunda-feira, 16 de maio 1796. O julgamento evidencia a vontade de excluí-las do mercado e cortar os laços que mantinham com o comércio oficial, pois, além das roupas miúdas para crianças que produziram a partir de velhas roupas, vendiam também mercadorias confiadas a elas por uma vendedora de usados. Perante a justiça, invocaram sua pobreza, os encargos de família e o fato de que seu comércio era tão modesto que acreditavam não terem que pagar licença. $\mathrm{O}$ advogado encarregado de defendê-las terminou ressaltando quanto essas práticas eram comuns, pois - ele diz, - "a esposa Moreau e a filha Toutain são como muitas cidadãs de todos os municípios da república que, como elas, fabricam roupas gastas para crianças a partir de velhos panos que procuram, incapazes de pagar a mínima contribuição, o investimento da maioria delas sendo inferior ao preço do menor imposto...." Essas mulheres foram vítimas da vontade

${ }^{6}$ A.N. BB 18822 Justice Seine-et-Marne citado por Cobb, 1985, p. 170-171. 
do legislador de regulamentar o comércio e mais ainda da luta entre comerciantes. Esse fenômeno de exclusão é aliás geral e Louis Sébastien Mercier denunciava, no seu "Quadro de Paris" (Tableau de Paris), espécie de crônica da vida quotidiana no século XVIII, os embargos que se multiplicam para disciplinar essas práticas:

Nada mais frequente, e nada que desonra mais nossa legislação. Vê-se frequentemente um oficial com ajudantes, correndo atrás de um vendedor de roupas miseráveis, ou atrás de um pequeno vendedor de ferragens que carrega uma loja portátil...

Despoja-se publicamente uma mulher que leva nas costas e na cabeça uns 40 pares de calças. Pegam-se esses trapos em nome da majestosa comunidade dos vendedores de objetos usados (...) Prende-se um homem de paletó que carrega algo envolvido no sobretudo. O que é encontrado? Sapatos novos que o infeliz havia escondido num pano de prato. Os sapatos são confiscados por ordenança, essa venda atentatória à Sapataria parisiense (Mercier, 1994 [1781-1789], t. II, cap. DLXXVI, p. 143-144.).

Assim, na França do século XVIII, todo mundo era mais ou menos vendedor, mas esse acesso ao mercado estava desaparecendo.

As diversas redes sociais nas quais os indivíduos se apoiavam dependiam ou dos laços horizontais ou dos laços verticais. Os primeiros agrupavam os parentes, os vizinhos, os amigos e os iguais na atividade, e os segundos as elites às quais habitantes das cidades e camponeses eram ligados pelo trabalho ou pelo poder. Mas, quer fossem verticais ou horizontais, todas as relações sociais eram atravessadas pela dívida. Se essas relações sociais não podiam responder, os indivíduos deviam então recorrer aos usurários. Pode-se ler esses círculos sucessivos como uma escala que inscreveria a relação de crédito em primeiro lugar nas diversas relações interpessoais que cercavam os indivíduos para progressivamente se libertar e acabar numa relação nitidamente econômica e despersonalizada.

Quando as relações de crédito existiam e não estavam reduzidas ao mesmo estado de miséria, em todos os meios sociais o parentesco próximo ajudava os seus. É difícil isolar os vizinhos e amigos das solidariedades familiares, todos preenchiam papéis semelhantes e, segundo o espaço social e as conjunturas, uns ou outros eram mais presentes (Fontaine, 1990, p.1433-1450). Aliás, as assembleias de parentes eram também dos vizinhos e amigos. Na cidade, vizinhos e amigos mais ricos assinavam os atestados de pobreza, adiantavam dinheiro, compareciam aos funerais, organizavam petições ou escreviam os pedidos que os pobres necessitavam (Jütte, 1994, p. 97).

Depois da família e dos vizinhos, era lançado apelo às elites tradicionais, aos notáveis e às pessoas para as quais as famílias trabalhavam. E aí, as respostas eram muito distintas segundo os grupos sociais. Os aristocratas eram não somente grandes sócios capitalistas para os seus camponeses, mas também aqueles que ao longo do antigo regime manifestavam a maior generosidade em relação aos pobres dos seus domínios. Essa atitude conservava alguma 
coisa dos contratos antigos nos quais os fracos se colocavam sob a proteção dos poderosos. Era também o grupo social que se portava com a maior mansidão com seus pobres devedores, abstendo-se de apressar o recebimento dos créditos pela venda forçada das terras, além de postergar a cobrança dos alugueis ou moderar os atrasos acumulados nos períodos de crise - os anos 1670, 1680 e depois de 1720 -, quando pouco aproveitaram da situação para excluir ou substituir seus arrendatários, permitindo atrasos e esquecendo dívidas dos anos ruins (Fontaine, 2008, cap. 1).

As relações verticais de trabalho na cidade e no campo tinham outra conotação. Ainda que encontremos algumas histórias edificantes de solidariedades urbanas, é claro que as solidariedades entre vendedores ou fabricantes e operários eram mais que restritas; os primeiros não sentiam nenhuma obrigação de empregá-los ou ajudá-los caso eles não precisassem economicamente. Os contratos de aprendizagem eram rudes quando falavam dos prazos durante os quais o aprendiz seria cuidado pelo seu patrão antes de ir ao Hospital: $^{7}$ entre 15 dias e 2 meses no máximo (Fontaine, 1990, p.1433-1450).

As relações de clientela e as lógicas do poder aldeão expressavam-se também por meio da dívida, que podia ainda atuar contra o devedor, mas o cultivo dessas relações constituía um primeiro seguro: o camponês teria durante a sua vida inteira teto e comida. Em troca, em todas as manifestações das lutas entre as famílias, o camponês traria seu apoio ao patrão e tão logo ele precisasse ofereceria sua força de trabalho. Como em todas as relações pessoais da época, os negócios somente eram acertados quando da morte do patrão ou do cliente (Fontaine, 2008, cap. 2).

Certos camponeses notáveis, como os cobradores de senhoria ou coletores de impostos na França e os procuradores (attorney) na Inglaterra, deixaram muitos inventários post mortem cuja enumeração das dívidas ativas mostravam a intensa atividade de prestamista (Anderson, 1968; Goubert, 1960, p. 175-176). Esses empréstimos eram para plantio, adiantamento de sementes, de madeira, de feno, de dinheiro para os impostos ou para os processos, credores de mais da metade das famílias da aldeia e de muitos outros das aldeias vizinhas. Com esses empréstimos, eles asseguravam seu poder e garantiam uma mão de obra dócil. Assim, o conjunto desses laços sociais levava ao superendividamento, em especial, dos pequenos camponeses e trabalhadores sazonais. Ora, vários sistemas de valor coexistiam na Europa dos séculos XVII e XVIII e faziam que o crédito funcionasse ora como proteção, ora como agente desestruturador das vidas. Bastava então que os credores não respeitassem as culturas que envolviam a dívida e protegiam o laço social para que o crédito se tornasse uma poderosa arma de empobrecimento. Assim, a dívida dizia, às vezes, da inclusão dos mais pobres em um conjunto protetor de comunidades diversificadas e, às vezes, da obrigação de assistência abstrata destinada

${ }_{7}$ L'hôpital em francês, ou mont-de-piété em português seriam algo próximo às Santas Casas de Misericórdia e instituições caritativa similares (Nota do tradutor) 
às instituições religiosas ou estatais que liberava os indivíduos da responsabilidade concreta de ajudar.

Os citadinos pobres souberam desenvolver complexas estratégias de poupança. Uma delas, reservada aos homens, remete ao último conjunto de solidariedades horizontais: as confrarias e corporações que tinham todas elas uma vontade de ajudar seus membros pobres; afiliação que procurava segurança econômica e estatuto distintivo no mundo do trabalho.

Foi possível reencontrar também verdadeiras estratégias de poupança e de colocações financeiras. Assim, na França, pessoas humildes, para evitarem viver a velhice no Hospital, investiam suas modestas poupanças nesses mesmos estabelecimentos, atraídos pelos expressivos rendimentos e a aparente segurança dessas instituições. As análises dos credores do Hospital de Aixen-Provence, bem como da Santa Casa de Marselha, atestam essa estratégia (Valran, 1979[1899], p. 205.). O reitor do Hospital descrevia ao intendente em 1762 os credores de seu estabelecimento:

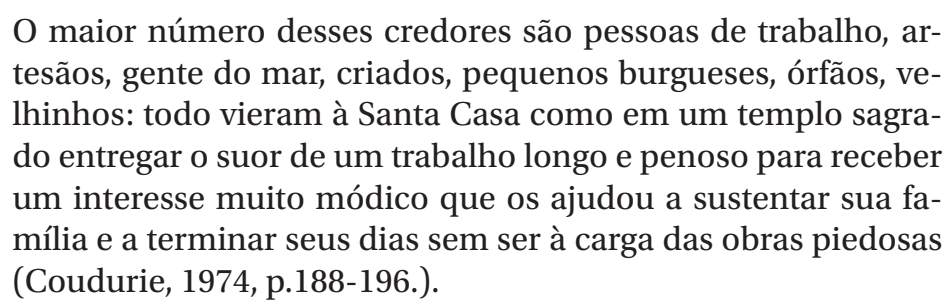

A análise dos participantes do estabelecimento de penhor parisiense no final do século XVIII mostra que o povo miúdo também não hesitava em investir lá suas economias. $\mathrm{O}$ crédito é igualmente uma forma de poupança. Emprestar mutuamente dinheiro, além de criar solidariedades era uma forma de poupança. Na França, às vezes, encontra-se nos arquivos mulheres como Françoise Moreau, antiga criada em Lyon, que escreveu de Grenoble em 10 de março de 1743 a uma lavadeira conterrânea para lhe pedir, entre outras, para recuperar o crédito de 21 sols que ela tinha com uma remendeira de meias da rua Bellecordière, pois "ela precisa de dinheiro". Pequeno empréstimo que a Deauphinoise não cobrou ao sair de Lyon e que somente a necessidade a fazia naquele momento recuperar. Solidariedade para Françoise Moreau, mas sem dúvida atividade anexa para Marguerite Lambert, uma lavadeira do Quai des Célestins, que deixou 153 libras de mobília e de objetos de uso no quarto onde morava, mas possuía crédito de 2.162 libras. Ela havia emprestado a diferentes pessoas, em uma ocasião, mais de 1.000 libras (Gutton, 1971, p. 8283). Revela-se aí toda uma atividade de crédito minúsculo dentro dos bairros em que as mulheres eram grandes atrizes.

As fronteiras eram particularmente porosas entre a solidariedade, a poupança e a entrada nos mercados informais de finanças. Assim, a aquisição de objetos de luxo era colocada entre a poupança e a entrada no mercado do dinheiro. Em Paris, os inventários post-mortem do século XVIII registravam um aumento espetacular dos relógios de bolso e dos objetos da moda ao longo 
do século (Roche, 1981, p. 226; Fairchilds, 1993, p. 228-248). As joias seguiram essa mesma tendência. Ora, esses relógios de bolso valiosos eram os objetos de predileção que as classes populares depositavam nas casas de penhor. Louis Sébastien Mercier assistiu à abertura da casa de penhoras de Paris em dezembro de 1777:

Nada comprova melhor a necessidade que a capital tinha desse lombard que a afluência inesgotável dos demandantes. Contam-se coisas tão singulares, tão incríveis que não ouso as expor aqui antes de colher informações mais particulares que me autorizam a certificá-las. Fala-se de 40 tonéis cheios de relógios de bolso de ouro, para expressar sem dúvida a quantidade prodigiosa que foi trazida. O que sei, é que vi no lugar 68 pessoas que, esperando sua vez, vinham cada um pedir um empréstimo que não ultrapassava seis libras. Um trazia suas camisas; esse um móvel; esse um resto de armário; outro suas fivelas de sapato, um quadro velho, uma roupa velha, etc. Diz-se que essa multidão se renova quase todos os dias, e isso dá uma ideia inequívoca da extrema penúria na qual é mergulhada a maior parte dos moradores (Mercier, 1994 [1781-1789], t. 1, p. 662-664, "Mont de piété")

O conjunto dessas estratégias remete ao modo pelo qual as classes populares procuravam conquistar o futuro, se precaver contra as crises que elas com certeza encontrariam e as atravessariam da melhor forma. Mas quando eram mais duramente atingidas do que o previsto, elas utilizavam suas poupanças; quando o crédito não bastava mais e o trabalho era impossível de achar em quantidade suficiente, o que elas faziam? Algumas fontes informam sobre essas escolhas dramáticas. Uma delas são as cartas que os pobres escreveram na Inglaterra para pedir a ajuda de instituições.

As famílias operavam certamente mudanças alimentares que é difícil de acessarmos e que fragilizavam a saúde dos indivíduos. Percebe-se bem em contrapartida o papel do crédito na alimentação e na moradia onde os atrasos de aluguéis acumulavam-se. Na alimentação, os padeiros eram os mais expostos e os raros livros de conta conservados mostram a amplitude do empréstimo para o consumo; os açougueiros igualmente, vendiam fiado (Montenach, 2009; Garden,1970, t. II, p. 47-80).

As famílias jogavam também com seu próprio tamanho utilizando o abandono de crianças, o hábito de confiá-las temporariamente ao Hospital ou a outros membros da família - principalmente aos avós - ou a outras famílias quando os filhos custavam caro para alimentar e não tinham ainda uma força de trabalho utilizável para oferecer. Nas regiões pobres, as famílias tinham o hábito de se livrar das crianças entre 7 e 12 anos. Elas as mandavam pedir esmolas, as confiavam a empreiteiros de mão de obra infantil, como limpadores de chaminés, até mesmo os deixavam no Hospital - e cada região tinha seus costumes em matéria de hospital - sabendo que eles seriam recolhidos e colocados como aprendizes, o que, afinal de contas, abriria para eles um futuro 
profissional (Fontaine, 1990, p. 1433-1450). Entretanto, ainda no século XVI, não somente os artesãos e os biscateiros mandavam seus filhos pedir esmola a partir de 7 anos mas também o Conselho da cidade mandava embora as crianças abandonadas da Santa Casa mendigar na mesma idade com um letreiro pendurado que explicava "que são pobres órfãos pedindo esmolas para Deus". Mas a população - meu exemplo aqui é de Lyon - se queixava de todas essas crianças berrando de fome e de frio noite e dia. A presença deles entre os mendigos da cidade foi um fator importante da reforma da assistência no século XVII (Davis, 1974, p. 771).

\section{Muitas mulheres sobreviviam utilizando seu saber de costureira para retrabalhar roupas de segunda mão}

Na França, o afluxo dos órfãos nos anos 1680 a La Grave, no alto Dauphiné, ${ }^{8}$ estudado a partir das reuniões de "parentes, vizinhos e amigos" registradas nos tabeliães (Fontaine, 1990, p. 1433-1450) permite ver as estratégias de utilização do Hospital, de seu envio em aprendizagem na casa de parentes emigrados, até mesmo os mandar pedir esmola nas estradas quando a venda dos bens das crianças mal permite os vestir. Essas práticas, bem como a migração, eram, possivelmente, formas de destruição da família, que se privava dos membros que partiam, quando esses decidiam não mais voltar, e se privava também de sua descendência, quando as crianças eram descartadas.

Em todo lugar se nota a extrema mobilidade dos locatários pois muitos se mudavam para alojamentos menos caros frente a impossibilidade de pagar os aluguéis bem como a sublocação de cômodos ou de camas. De fato, o atraso no pagamento dos aluguéis era a principal causa do endividamento. Os atrasos de aluguel com penhora ou apenas ameaças lançavam nas estradas indivíduos e famílias. Lyon, ${ }^{9}$ Rennes, ${ }^{10}$ Beauvais, onde estudos pormenorizados permitem penetrar no endividamento citadino, atestam o papel crucial dos atrasos de aluguel no empobrecimento. Medir o número médio de termos de atraso é aliás uma medida da pobreza citadina e de suas flutuações.

Utilizar a caridade temporariamente ou definitivamente entrando no Hospital fazia parte das soluções. Na maior parte do tempo, os socorros da

\footnotetext{
${ }^{8}$ Vila de La Grave na região dos Alpes. Nota do tradutor.

9 Jean-Pierre Gutton (1971, 132-135) fornece numerosos exemplos para Lyon, como o caso de um operário em seda que saiu de Lyon porque ele estava sendo perseguido por seus credores. Sua mobília vendida em leilão rendeu 459 libras 12 sols e suas dívidas eram de 356 libras 5 sols e 9 deniers. Um mestre carpinteiro "acossado por seus credores" "sumiu" deixando sua mulher e seus seis filhos. Cinco meses depois, o proprietário promoveu embargo por atraso de aluguel e dois dias depois a mulher sumiu levando os dois filhos mais velhos. Quando em 1686 seu locatário morreu, Pierre David se fez representar quando do inventário para salvaguardar seus direitos, mais de dois anos de atraso de aluguel com valor de 54 libras por ano. Infelizmente, o defunto apenas deixou 56 libras.

10 Na Rennes do século XVIII, Christine Chapalain-Nougaret (1989, p. 122-123) levantou os inventários postmortem de pobres cobertos de dívidas e com atraso no aluguel: a avaliação de seus bens - em torno de 10 libras - sendo inferior ao aluguel anual do pequeno cômodo de habitação.
} 
caridade eram complementares: não eram, aliás, nunca suficientes para sustentar totalmente as pessoas. Sem dúvida também porque essas pessoas integravam os estigmas que a sociedade colocava sobre os pobres assistidos, elas conservavam atividades que os arquivos das instituições de caridade esclarecem. As atividades femininas mais frequentes, já que a imensa maioria dos pobres é de mulheres, mostram que algumas se prostituíam, que muitas pediam esmolas e que o maior número exercia pequenos ofícios: vendedoras ambulantes de gêneros alimentícios (frutas, ovos, ostras), de jornais (em certas cidades como Paris ou Madri, as autoridades reservam a venda ambulante a seus pobres); algumas se tornavam professoras de escolas, tomavam conta de crianças, de doentes e de velhos, limpavam e lavavam a roupa, outras trabalhavam em quarto e costuravam roupas ou confeccionavam luvas, algumas carregavam água, outras chegavam mesmo a tomar conta de lojas e de botequins (Boulton, 2000, p. 47-70).

Outro traço da análise dos arquivos mostra que os pobres faziam tudo para continuar a viver em casa e não ir para essas instituições. Eis o exemplo de Diane Lothiane em Londres: "ela somente permaneceu um mês na casa de caridade paroquial (parish workhouse) em 1725 e a deixou para tentar dar conta de se sustentar sozinha". Era conhecida da justiça local - que administrava os socorros - desde 1708, quando devia ter quase 60 anos; naquela altura, ela não sabia se era viúva. Com seu marido haviam sido comerciantes e pagavam impostos, mas ele foi para as Índias (East Indies) havia sete anos e a partir daí sua situação se alterou: ela teve que se mudar para uma rua pobre. Tinha também uma filha de 20 anos da qual nada sabemos. Começou a receber ajuda de um shilling por semana em 1714, ajuda que passou para 2 shillings antes de sua entrada na workhouse em 1725: ela tinha então 76 anos. (Boulton, 2000, p. 47-70).

Tim Hitchcock ${ }^{11}$ mostrou que a St Margaret's, no bairro de Westminter, 108 pessoas recebiam socorros em 1726 . Todos eles foram admitidos na workhouse desde sua abertura, mas somente 41 aceitaram ficar lá, os outros preferiram renunciar à sua pensão semanal.

As famílias utilizavam essas instituições de caridade temporariamente: somente um terço daqueles que foram admitidos em St. Martin morreu na instituição e a maior parte dos pobres acolhidos foi resgatada por um parente depois de uma estadia relativamente curta. Os estudos sobre Barcelona mostram a mesma coisa (Carbonell i Esteller, 2000, p. 71-92).

Gostaria de concluir esse conjunto de análises que evidenciam o trabalho incessante das famílias pobres para prever um futuro incerto com a resposta que Fígaro dá ao conde Almaviva no Casamento de Fígaro, de Beaumarchais: "perdido na multidão obscura, apenas para sobreviver tive que desenvolver mais ciência e cálculos do que se gastou durante 100 anos para governar todas as Espanhas". ${ }^{2}$

" HITCHCOCK, Tim. Habits of industry: the eighteenth-century english workhouse movement, 1993, citado por Boulton, 2000, p.47-70.

${ }^{12}$ Beaumarchais, Le Mariage de Figaro, ato V, cena 3. 
A conferência "Pobreza, Crédito e Redes Sociais na Europa PréIndustrial" foi proferida por Laurence Fontaine na Universidade Federal Fluminense em 23 de setembro de 2014. Com formação em história e sociologia, Laurence Fontaine é diretora de pesquisa do Centre Nacional de la Recherche Scientifique (CNRS) $e$ pesquisadora vinculada ao Centre Maurice Halbwachs (CNRSENS-EHESS). Sua atividade na UFF fez parte de uma "missão" de trabalho realizada durante o mês de setembro no Brasil no âmbito do projeto CAPES-COFECUB, "Modos de governo e práticas econômicas ordinárias", coordenado por Benoît de L' Estoile, CNRS-ENS e Federico Neiburg, PPGAS/MN. A conferência na UFF foi viabilizada graças à parceria entre o Núcleo de Pesquisa em Cultura e Economia (NUCEC-MN), o Núcleo Fronteiras e Transformações das Práticas Estatais e Políticas (PPGS-UFF) eo Laboratório de História Econômica-Social (POLIS-UFF). Dentre as publicações de Laurence Fontaine destacamos: L'Economie morale. Pauvreté, crédit et confiance dans l'Europe préindustrielle. Paris: Gallimard, 2008 e Le Marché, Histoire et usages d'une conquête sociale. Paris: Gallimard, 2014.

\section{Referências bibliográficas}

AGO, Renata. Economia Barocca. Mercato e istituzioni nella Roma del Seicento. Roma: Donzelli, 1998.

ANDERSON, B. L. The attorney and the early capital market in Lancashire In: HARRIS, John Raymond (Ed.). Liverpool and Merseyside. Essays in the economic and social history of the Port and Hinterland. London: Routledge, 1968.

BOULTON, Jeremy. 'It is extreme necessity that makes me do this': some 'survival strategies' of pauper households in London's west end during the early eighteenth century In: FONTAINE, Laurence; SCHLUMBOHM, Jürgen (Eds.) Household strategies for survival, 1600-2000. Fission, faction and cooperation. Cambridge: Cambridge University Press, 2000, p.47-70.

CARBONELL i ESTELLER, Montserrat. Sobreviure a Barcelona. Dones, pobresa i assistència al segle XVIII. Barcelone : Eumo Editorial, 1997.

. Using microcredit and restructuring households: two Complementary survival strategies in late-eighteenth-century Barcelona In: FONTAINE, Laurence; SCHLUMBOHM, Jürgen (Eds.) Household strategies for survival, 1600-2000. Fission, faction and cooperation. Cambridge: Cambridge University Press, 2000, p. 71-92.

CASTEL, Robert. Les métamorphoses de la question sociale. Une chronique du salariat. Paris : Fayard, 1995.

CHAPALAIN-NOUGARET, Christine. Misère et assistance dans le pays de Rennes au XVIIIe siècle. Rennes: Cid éditions, 1989.

COBB, Richard. La mort est dans Paris - enquête sur le suicide, le meurtre et autres morts subites à Paris, au lendemain de la terreur, octobre 1795-septembre 1801, Vendémiaire an IV-Fructidor an IX. Paris: Chemin Vert, 1985.

CONDURIE, Marcel. La dette des collectivités publiques de Marseille au XVIIIe siècle. Du débat sur le prêt à intérêt au financement par l'emprunt. Marseille: IHP, 1974. 
DAVIS, Natalie Zemon. Assistance, humanisme et hérésie: le cas de Lyon In : MOLLAT, Michel (Dir.). Études sur l'histoire de la pauvreté (Moyen âge - XVIe siècle). Paris: Publications de la Sorbonne, t. 2, 1974, p. 761-822.

FAIRCHILDS, Cissie. The production and marketing of populuxe goods in eighteenth-century Paris In: BREWER, John; PORTER, Roy (Eds.). Consumption and the world of goods. London: Routledge, 1993, p. 228-248.

FONTAINE, Laurence. Solidarités familiales et logiques migratoires en pays de montagne à l'époque moderne. Annales ESC, 6, p.1433-1450, 1990.

; SCHLUMBOHM, Jürgen (Eds.) Household strategies for survival, 1600-2000. Fission, faction and cooperation. Cambridge: Cambridge University Press, 2000.

. L'économie morale. Pauvreté crédit et confiance dans l'Europe préindustrielle. Paris: Gallimard, 2008; tradução inglesa: The Moral Economy. Poverty, credit and thrust in early modern Europe. New York/London: Cambridge University Press, 2014.

FREY JR., Dennis A. Industrious households: survival strategies of artisans in a southwest german town during the eighteenth and early nineteenth centuries In: FONTAINE, Laurence; SCHLUMBOHM, Jürgen (Eds.) Household strategies for survival, 1600-2000. Fission, faction and cooperation. Cambridge: Cambridge University Press, 2000. p.115-135.

FURETIÈRE, Antoine. Dictionnaire universel. La Haye-Rotterdam : A. et R. Leers, 1690.

GARDEN, Maurice. Bouchers et boucheries de Lyon au XVIIIe siècle. 9è Congrès national des sociétés savantes, Strasbourg et Colmar 1967, section Histoire moderne et contemporaine. Paris: Bibliothèque Nationale, 1970, t. II, p. 47-80.

GOUBERT, Pierre. Beauvais et le beauvaisis de 1600 à 1730: contribution à l'histoire sociale de la France du XVIIe siècle. Paris : SEVPEN, 1960

GUTTON, Jean-Pierre. La société et les pauvres. L'exemple de la généralité de Lyon (1534-1789). Paris : Les Belles Lettres, 1971.

HENDERSON, John; WALL, Richard (Eds.). Poor women and children in the european past. London: Routledge, 1994.

HINDLE, Steve. On the parish?:The micro-politics of poor relief in rural England, c.1550-1750. Oxford: Oxford University Press, 2004.

HORDEN, Peregrine; SMITH, Richart (Eds.). The locus of care: families, communities and institutions and the provision of welfare since antiquity. London: Routledge, 1998.

HUFTON, Olwen. The poor of eighteenth-century France, 1750-1789. Oxford: Oxford University Press, 1974.

JÜTTE, Robert. Poverty and deviance in early modern Europe. Cambridge: Cambridge University Press, 1994.

LOMBARDI, Daniela. Povertà maschile, povertà femminile: L'ospedale dei mendicanti nella Firenze dei Medici. Bologna: Il Mulino, 1988.

MERCIER, Louis-Sébastien. Tableau de Paris, 1781-1789, edição de BONNET, Jean-Claude. Paris: Mercure de France, 2 tomos, 1994.

MOLLAT, Michel. Les pauvres au moyen age. Paris: Hachette, 1978, pp. 311-312.

MONTENACH, Anne. Espaces et pratiques du commerce alimentaire à Lyon au XVIIe siècle. L'économie du quotidien. Grenoble: Presses Universitaires de Grenoble, 2009.

PROCCACCI, Giovanna. Gouverner la misère. La question sociale en France (1789-1848). Paris : Seuil, 1993.

ROCHE, Daniel. Le Peuple de Paris. Essai sur la culture populaire au XVIIIe siècle. Paris: Aubier, 1981.

VALRAN, Gaston.. Misère et charité en Provence au XVIIIe siècle. Essai d'histoire sociale. Paris, 1899; Genève: Mégariotis Reprints, 1979.

WOOLF, Stuart. The poor in western Europe in the eighteenth and nineteenth centuries. London: Methuen, 1986. 